\title{
Bärbel Dümler
}

\section{Zeno von Verona zu heidnischer Kultur und christlicher Bildung}

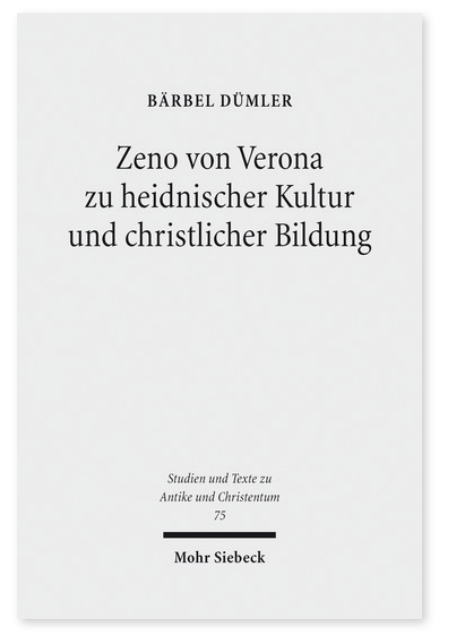

2013. XIV, 661 Seiten. STAC 75

SBN 978-3-16-152700-5

DOI 10.1628/978-3-16-152700-5

eBook PDF 129,00€

ISBN 978-3-16-150224-8

fadengeheftete Broschur 129,00€
Bärbel Dümler untersucht die Traktate des Zeno von Verona, das älteste erhaltene lateinische Predigtcorpus aus der Zeit zwischen 360 und 380 n. Chr. Auf philologischer Grundlage analysiert sie zunächst das Verhältnis des Bischofs zum Heidentum entsprechend dem stoischen Schema der Theologia tripartita. Zenos Äußerungen zu heidnischem Kult, Göttern und mythologischen Gestalten und deren Darstellung sowie zu Philosophie und Intellektualität lassen erkennen, dass er das Christentum für die in jeder Hinsicht überlegenere Religion hält. Anschließend widmet sich die Autorin dem Gegenentwurf des Zeno zur von ihm verworfenen heidnischen Kultur: Entscheidender Unterschied ist die Ausrichtung aller Komponenten des Gegenentwurfs, nämlich religiösen Sachwissens, ethischen Wissens und ethischen Könnens, auf Gott hin, wie dies im auf Meister Eckhard zurückgehenden, hier rückübertragenen Terminus 'Bildung' zum Ausdruck kommt.

Bärbel Dümler Studium der Katholischen Theologie, Latinistik, Christlichen Archäologie sowie Sprachen und Kulturen des Christlichen Orients in Bochum, Rom, Bonn und Tübingen; 1989-93 Wissenschaftliche Mitarbeiterin an der KatholischTheologischen Fakultät der Ruhr-Universität Bochum; 2001-06 an der Katholisch-Theologischen Fakultät der Eberhard-KarlsUniversität Tübingen, 2008-09 im Fachbereich Geschichte und Soziologie der Universität; 2005 Promotion; seit 2005 Lehrbeauftragte, seit 2012 Wissenschaftliche Mitarbeiterin an der Abteilung für Orient- und Islamwissenschaft der EberhardKarls-Universität Tübingen.
Jetzt bestellen:

https://mohrsiebeck.com/buch/zeno-von-verona-zu-heidnischer-kultur-und-christlicher-bildung-9783161527005?no_cache=1 order@mohrsiebeck.com

Telefon: +49 (0)7071-923-17

Telefax: $+49(0) 7071-51104$ 